\title{
(2) Hepatic sarcoidosis resembling primary sclerosing cholangitis
}

\author{
Ying Chen, ${ }^{1}$ Camelia Ciobanu, ${ }^{2}$ Laurel Mohrmann ${ }^{3}$
}

${ }^{1}$ Internal Medicine, Montefiore Medical Center, Bronx, New York, USA

IInternal Medicine, St. Barnabas Hospital, Bronx, NY, USA

${ }^{3}$ Hospital Medicine, Montefiore Medical Center, Bronx, New York, USA

\section{Correspondence to}

Dr Ying Chen;

ychen3@montefiore.org

Accepted 24 August 2021

\section{SUMMARY}

We report the case of a 29-year-old man who presented with progressive weight loss, night sweats, abdominal pain and pruritus who was found to have obstructive jaundice and cholestatic pattern of liver injury on laboratory workup. Though findings on magnetic resonance cholangiopancreatography were initially concerning primary sclerosing cholangitis, he was ultimately diagnosed with biliary sarcoidosis after a liver biopsy. This case brings attention to the rare phenomenon of hepatic sarcoidosis causing hyperbilirubinemia and highlights the importance of reaching the correct diagnosis early, as the patient's symptoms improved after initiation of steroids.

\section{BACKGROUND}

Sarcoidosis is a multisystemic granulomatous disease of unknown origin that affects individuals worldwide, with highest incidence and prevalence in African Americans. ${ }^{1}$ It is characterised by the presence of non-caseating granulomas on tissue biopsy and can involve any organ, including the liver. Hepatic sarcoidosis was found in $11.5 \%$ of patients with sarcoidosis and clinical manifestation vary significantly; most of the patients are asymptomatic but 5\%-15\% develop signs and symptoms of cholestasis, portal hypertension, cirrhosis and Budd-Chiari syndrome. ${ }^{2-7}$

Cholestatic liver disease in hepatic sarcoidosis could be intrahepatic or extrahepatic. Intrahepatic sarcoidosis can resemble primary sclerosing cholangitis (PSC) or in rare circumstances these two entities can coexist. ${ }^{8-12}$

We present a case report of a patient with radiological findings 'typical' for PSC and liver biopsy showed non-caseating granulomas consistent with hepatic sarcoidosis.

\section{CASE PRESENTATION}

A 29-year-old man with no significant medical history presented to the emergency department as referred by his general practitioner for scleral icterus. His symptoms began 6 months ago with shortness of breath, dry cough, nausea, vomiting, epigastric abdominal pain, fatigue and night sweats along with unintentional weight loss of 60 lbs. For the past 3 weeks he experienced intense body itching that is worse at night and unalleviated with over-the-counter antihistamines. $\mathrm{He}$ also noticed yellow discolouration of his eyes 3 days ago. He does not take any prescription medications or herbal supplements. He denies tobacco, alcohol, or recreational drug use. Family history is insignificant.

On review of vital signs, the patient was afebrile, normotensive with blood pressure $132 / 82 \mathrm{~mm} \mathrm{Hg}$ and heart rate of $87 \mathrm{bpm}$. Physical examination was pertinent for icteric sclera, but otherwise unremarkable.

\section{INVESTIGATIONS}

Initial laboratory analysis was significant for alanine aminotransferase of $98 \mathrm{U} / \mathrm{L}$, aspartate aminotransferase of $124 \mathrm{U} / \mathrm{L}$ and alkaline phosphatase (ALP) of $790 \mathrm{U} / \mathrm{L}$ demonstrating a mixed pattern cholestatic and hepatocellular liver injury. Furthermore, total bilirubin was $11.1 \mathrm{mg} / \mathrm{dL}$ with a direct bilirubin of $8.1 \mathrm{mg} / \mathrm{dL}$. The rest of the initial laboratory workup can be found in table 1 .

Chest X-ray demonstrated bilateral hilar lymphadenopathy. A right upper quadrant abdominal ultrasound showed no stones within the gallbladder, a normal common bile duct measuring $0.2 \mathrm{~cm}$ and no intrahepatic biliary ductal dilatation.

Further testing revealed absence of autoantibodies, including negative antinuclear antibody, PR3-ANCA, anti-liver-kidney-microsomal antibody, anti-mitochondrial antibody (AMA) and smooth muscle antibody. The patient had a normal IgG4 level. Eventually, an ACE level returned elevated at $104 \mathrm{U} / \mathrm{L}$, and soluble interleukin-2 receptor levels elevated to $2576 \mathrm{U} / \mathrm{mL}$. He underwent Magnetic resonance cholangiopancreatography (MRCP) which showed peripheral intrahepatic biliary ductal dilatation consistent with changes of primary sclerosing cholangitis (figure 1). A liver biopsy performed by the interventional radiology team showed non-caseating granulomas (figure 2A,B). A CT of the chest without contrast confirmed bilateral hilar and mediastinal adenopathy, but showed no parenchymal lung disease. Given the diagnostic uncertainty, he underwent a colonoscopy, which was unremarkable.

\section{DIFFERENTIAL DIAGNOSIS}

The differential is broad in a patient presenting with jaundice and pruritus whose laboratory workup show conjugated hyperbilirubinemia. A useful branch point is determining if the obstruction is extrahepatic or intrahepatic. A history that is inconsistent with an acute presentation and an unremarkable right upper quadrant ultrasound narrows the differential to intrahepatic causes of cholestasis. With findings of ductal dilatation and 


\begin{tabular}{lll}
\hline Table 1 & Laboratory work at admission & \\
\hline Variable & On admission & Reference range \\
\hline Sodium (mEq/L) & 134 & $135-145$ \\
\hline Potassium (mEq/L) & 4.3 & $3.5-5.0$ \\
\hline Chloride (mEq/L) & 97 & $98-108$ \\
\hline Carbon dioxide (mEq/L) & 23 & $20-30$ \\
\hline BUN (mg/dL) & 9 & $5-20$ \\
\hline Creatinine (mg/dL) & 0.89 & $<1.30$ \\
\hline ALP (U/L) & 790 & $<130$ \\
\hline AST (U/L) & 124 & $<50$ \\
\hline ALT (U/L) & 98 & $<40$ \\
\hline Albumin (g/dL) & 3.1 & $3.5-5.0$ \\
\hline Total bilirubin (mg/dL) & 11.1 & $<1.2$ \\
\hline Direct bilirubin (mg/dL) & 8.1 & $<0.5$ \\
\hline Cholesterol (mg/dL) & $>600$ & $0-200$ \\
\hline Triglycerides (mg/dL) & 305 & $20-190$ \\
\hline HDL (mg/dL) & 13 & $55-999$ \\
\hline LDL (mg/dL) & $>526$ & $0-129$ \\
\hline ALP allige & & \\
\hline
\end{tabular}

ALP, alkaline phosphatase; ALT, alanine aminotransferase; AST, aspartate aminotransferase; BUN, Blood urea nitrogen; HDL, High density lipoprotein; LDL, Low density lipoprotein.

non-necrotising granulomas on biopsy, the leading differential for our patient included primary sclerosing cholangitis, primary biliary cholangitis, and biliary sarcoidosis.

\section{TREATMENT}

Patient found mild symptomatic relief with cholestyramine and ursodiol. After a negative fungal workup, he was discharged home on budesonide $3 \mathrm{mg}$ two times a day.

\section{OUTCOME AND FOLLOW-UP}

On outpatient follow-up, he reported doing well since discharge. His jaundice and pruritus have improved. Three months after

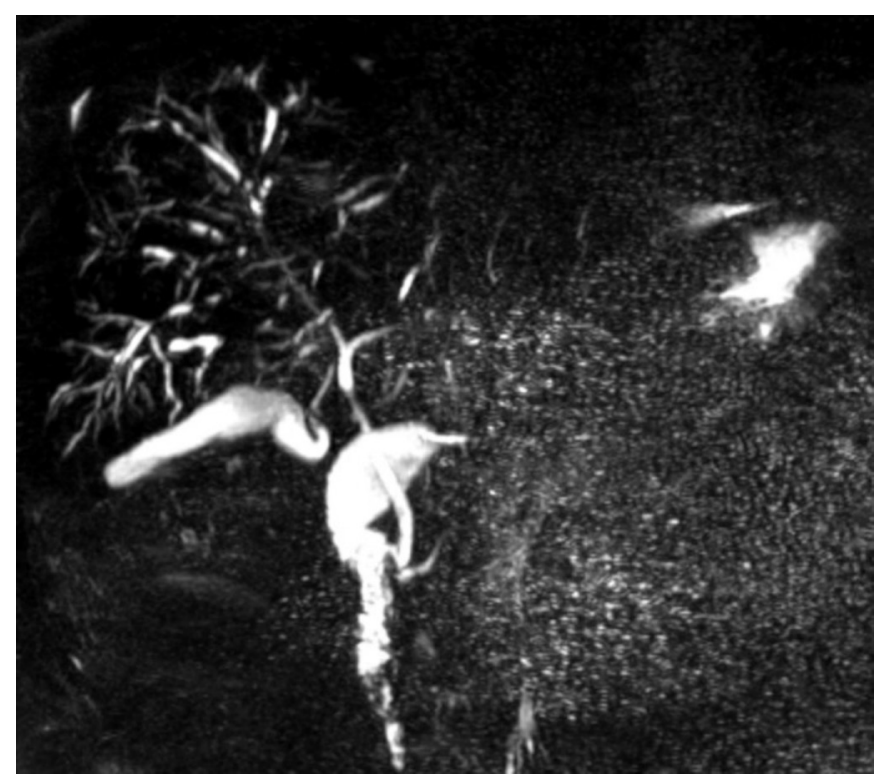

Figure 1 Peripheral intrahepatic biliary ductal strictures and dilatation concerning for changes of PSC. There is no extrahepatic biliary dilatation. No focal hepatic lesions. Liver shows normal portal vein and hepatic vein enhancement. starting steroids, his transaminases also normalised (table 2). Interestingly, ALP level remained elevated.

\section{DISCUSSION}

Though systemic sarcoidosis can frequently involve the liver, the granulomatous infiltration is only clinically significant in $5 \%-15 \%$ of cases. ${ }^{5}$ Biliary sarcoidosis leading to symptoms of cholestasis have been reported in literature in a dozen of cases; among many of these an alternative diagnosis was first considered, PSC being the top contender. ${ }^{11}{ }^{13-15}$ Overall, patients' presentations ranged from minimal symptoms to biliary sepsis, ${ }^{16}$ however, jaundice and elevated ALP levels are common findings. Non-invasive (ie, MRI) and biliary tree imaging (ie, MRCP) demonstrate stricture or 'beading' of intrahepatic biliary ducts, and less commonly, extrahepatic involvement. ${ }^{13}$ Interestingly,

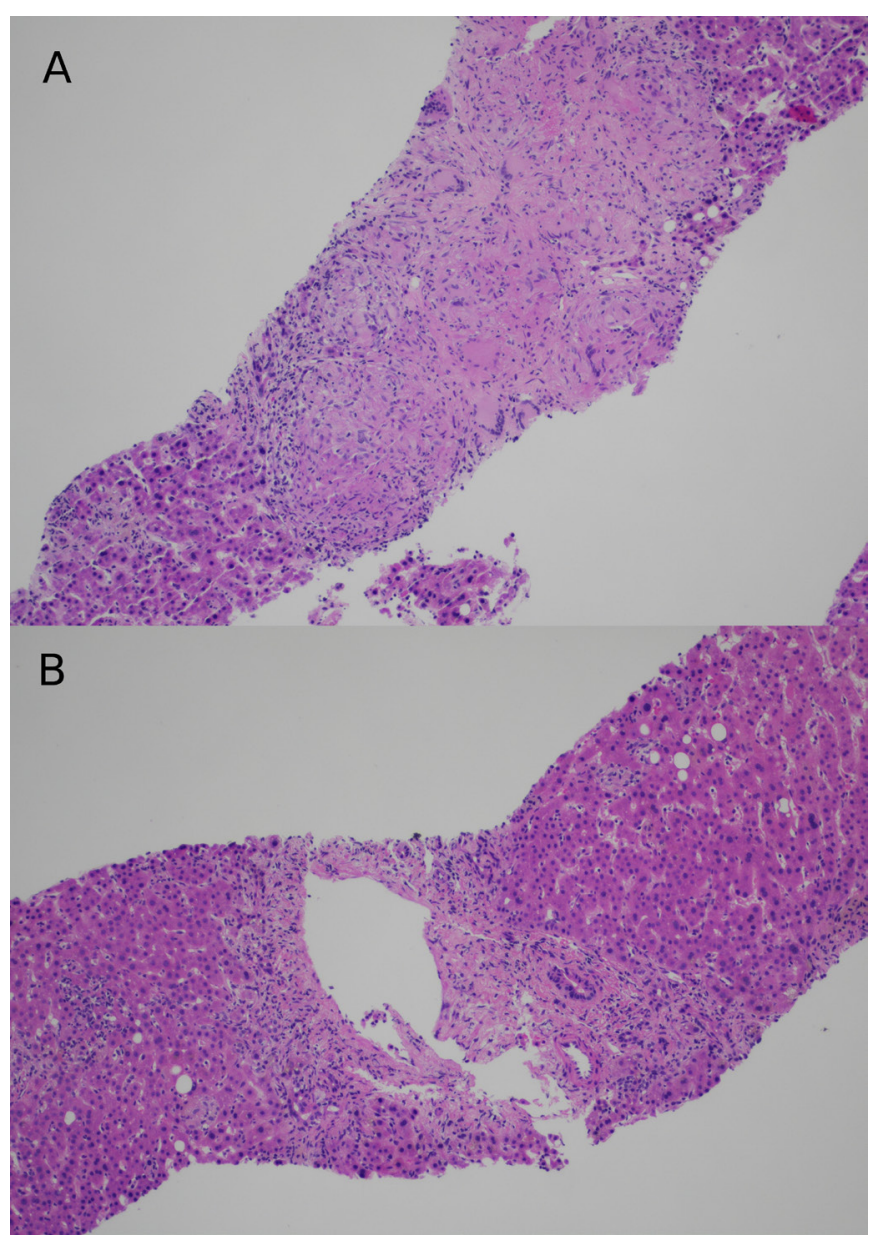

Figure 2 (A) This is a representative picture of the liver biopsy, demonstrating a granulomatous nodule forming in a background of otherwise unremarkable hepatic parenchyma. The granuloma consists of an aggregate of histiocytes (cells with eosinophilic cytoplasm and elongated nuclei) and giant cells (large eosinophilic cells with numerous nuclei arranged in crescent shape). This finding is characteristic, while not specific, for sarcoidosis. (H\&E stain, 100x magnification). (B) The representative picture of the portal tract of the liver biopsy shows a mild ductular reaction (bile duct proliferation) and mild lymphocytic infiltration of the portal tract. There is a lack of inflammation of the bile duct, however, as the lymphocytes are not infiltrating the ductal epithelium. Moreover, the characteristic periductal fibrosis (onionskinning) typically seen in primary sclerosing cholangitis is not observed in the entire biopsy. (H\&E stain, 100x magnification). 
Table 2 Hepatic function tests on discharge prior to steroids initiation and at 3 months and 6 months

\begin{tabular}{llll}
\hline Variable & At discharge & $\begin{array}{l}3 \text { months follow- } \\
\text { up }\end{array}$ & $\begin{array}{l}6 \text { months } \\
\text { follow-up }\end{array}$ \\
\hline $\begin{array}{lll}\text { Albumin (g/dL) } \\
\begin{array}{l}\text { Total bilirubin (mg/ } \\
\text { dL) }\end{array}\end{array}$ & 3.1 & 3.6 & 3.8 \\
$\begin{array}{l}\text { Direct bilirubin } \\
\text { (mg/dL) }\end{array}$ & 6.6 & 0.6 & 0.7 \\
ALP (U/L) & 576 & 0.4 & 0.4 \\
AST (U/L) & 191 & 552 & 410 \\
ALT (U/L) & 169 & 46 & 48 \\
\hline
\end{tabular}

ALP, alkaline phosphatase; ALT, alanine aminotransferase; AST, aspartate aminotransferase.

most reported cases proceed to Endoscopic retrograde cholangiopancreatography (ERCP) after a cross-sectional imaging modality. While more invasive, ERCP has the ability to obtain brush cytology in cases where cholangiocarcinoma is high on the differential. As a sum, these cases demonstrate that the correct diagnosis can save the patient from invasive procedures, emotional stress in cases of misdiagnosed cholangiocarcinoma, ${ }^{17}$ and even surgery, such as liver transplantation and exploratory laparotomies. ${ }^{18}$

The leading mimicker PSC is a chronic, progressive disease that insidiously destroys the biliary ducts and eventually leads to cirrhosis and liver transplantation. It is more common in men than women and has a strong association with inflammatory bowel disease. Anti-neutrophil cytoplasmic antibodies, and more recently, the subtype PR3-ANCA, are specific but poorly sensitive $(38.5 \%)$ for PSC. ${ }^{19}$ Unlike sarcoidosis, PSC does not have systemic manifestations, but instead it is associated with other autoimmune diseases such as hypothyroidism, type 1 diabetes mellitus and autoimmune hepatitis. ${ }^{20}$ Interestingly, granulomas can be found in $5 \%$ of liver biopsies in patients with confirmed PSC. ${ }^{20}$ Of note, at least two cases of coexisting diagnosis of PSC and sarcoidosis have been described. In one, a patient with ulcerative colitis was diagnosed with PSC, and 1 year later developed pulmonary sarcoidosis. ${ }^{21}$ Another case featured a patient with 6-year history of sarcoidosis who was found to have PSC and succumbed to cholangiocarcinoma. ${ }^{22}$ Both authors propose shared pathogenesis in immunological pathways. On liver biopsy, neither patient had granulomas. A brief overview of the similarities and differences of PSC and hepatic sarcoidosis have been summarised in table 3 .

Other granulomatous diseases of the liver exist, such as primary biliary cholangitis. The two can be differentiated based on the characteristics of the granuloma-in PBC, granulomas tend to be portal based and poorly formed whereas in sarcoidosis granulomas are well formed and associated with presence of giant cells. ${ }^{23}$ Additionally, AMA is 90\% sensitive and specific to PBC. The role of ACE in diagnosing sarcoidosis is limited due to its high levels in other granulomatous diseases and its low sensitivity, around $40 \%-60 \% .^{24}$ Biopsy is the gold standard for establishing the diagnosis, but a biopsy taken at the time of extensive cholestatic injury may only show nonspecific changes, and occasionally a second biopsy after the initial insult has resolved is needed for diagnosis. ${ }^{14} 1625$

Oral glucocorticoids are the most common first-line treatment. Response to steroid therapy varies; most patients with biliary sarcoidosis in case reports have resolution of symptoms and improvement in liver function tests with a single short course. ${ }^{11} 1315$ More extensive pulmonary involvement appears to predict persistent symptoms and liver enzyme elevations after steroids. ${ }^{26}$ There have not been trials to study treatment in biliary sarcoidosis. In a retrospective study of 27 patients with hepatic sarcoidosis, $83 \%$ responded to medical treatment with either oral glucocorticoids, anti-metabolites or biological agents. In this group, 40\% (9 out of 22) of patients who initially presented with elevated ALP had levels that were lowered but not normalised, similar to that in our patient. ${ }^{5}$ In a similar study, 345 patients with sarcoidosis at a single US centre were screened for hepatic involvement-19 patients had abnormal liver tests, liver imaging or abnormal liver at autopsy (3 patients). ${ }^{27}$ Of the patients who received oral glucocorticoids, $27 \%$ of patients had lower but not normalised ALP at the end of follow-up. Lack of normalisation of the ALP was not correlated with worse outcome (ie, development of cirrhosis) in this study. ${ }^{27}$

Both studies were conducted to identify hepatic involvement retrospectively in patients with sarcoidosis. None of

Table 3 Comparison of PSC and hepatic sarcoidosis

\begin{tabular}{|c|c|c|}
\hline & PSC & Hepatic sarcoidosis \\
\hline Epidemiology & $\begin{array}{l}\text { Incidence: } 1 \text { in } 100000 . \\
\text { Men in fourth decade of life. } \\
\text { Strong association with IBD. }\end{array}$ & $\begin{array}{l}\text { Incidence of sarcoidosis: } 1-40 \text { in } 100000 \text { with symptomatic liver involvement } \\
\text { in } 5 \%-30 \% \text { (up to } 80 \% \text { have asymptomatic involvement). Women }>\text { men. } 3 \times \\
\text { higher incidence in AA. }\end{array}$ \\
\hline Clinical presentation & $\begin{array}{l}\text { Abdominal pain, pruritus, diarrhoea, jaundice, fatigue and fever, but } \\
\text { many patients are asymptomatic and diagnosed on incidental laboratory } \\
\text { work. }\end{array}$ & Jaundice, nausea, vomiting, abdominal pain and hepatosplenomegaly. \\
\hline Serological markers & $\begin{array}{l}\text { Elevated ALP, elevated aminotransferase levels but less than three times } \\
\text { upper limit. Bilirubin is normal in } 60 \% \text { of patients. Positive ANCA }(84 \%) \text {, } \\
\text { anticardiolipin antibodies }(66 \%) \text { and ANA (53\%). }\end{array}$ & $\begin{array}{l}\text { Elevated ALP, ALT and AST. Negative ANA, AMA and ASMA. Normal IgG, } \\
\text { normal or elevated ACE. Normal or elevated calcium and vitamin D. }\end{array}$ \\
\hline Imaging features & $\begin{array}{l}\text { Multifocal intrahepatic and/or extrahepatic biliary strictures. 'Beading } \\
\text { appearance'. }\end{array}$ & $\begin{array}{l}\text { No imaging findings are sensitive or specific for diagnosis. May show diffuse } \\
\text { heterogeneity of the hepatic parenchymal on cross-sectional imaging. }\end{array}$ \\
\hline Histology & $\begin{array}{l}\text { Cholangitis, periductal fibrosis, ductular reaction and ductopenia. 'Onion } \\
\text { skin' appearance (specific but not sensitive). }\end{array}$ & $\begin{array}{l}\text { Non-caseating granulomas with macrophages with surrounding inflammatory } \\
\text { cells. }\end{array}$ \\
\hline Natural history & $\begin{array}{l}\text { Progresses to end-stage liver disease requiring liver transplant. At } \\
\text { increased risk of developing cholangiocarcinoma. }\end{array}$ & $3 \%-18 \%$ develop portal hypertension. \\
\hline Treatment & $\begin{array}{l}\text { No targeted medical therapy. Liver transplantation only curative } \\
\text { treatment. }\end{array}$ & $\begin{array}{l}\text { Corticosteroids normalise liver tests and reduce granulomas, but they may not } \\
\text { prevent progression. }\end{array}$ \\
\hline
\end{tabular}

AA, African americans; ALP, alkaline phosphatase; ALT, alanine aminotransferase; AMA, Antimitochondrial antibody ; ANA, Antinuclear antibody; ANCA, Antineutrophil cytoplasmic antibodies; ASMA, Anti-smooth muscle antibody ; AST, aspartate aminotransferase; IBD, Inflammatory bowel disease; PSC, primary sclerosing cholangitis. 
the patients in the Ungprasert study presented with jaundice or pruritus, and only a quarter in Sedki's group experienced cholestatic symptoms. Consequently, the conclusions drawn from these patients may not apply to patients whose disease primarily involves the biliary tree. An early response to steroids and the lack of extensive systemic involvement seems to predict a better outcome, however, it is not known what factors predict a favourable response to steroids. More research is needed to delineate the optimal treatment and natural history of sarcoidosis involving the hepatobiliary system.

\section{Learning points}

- Systemic sarcoidosis can frequently involve the liver and granulomatous infiltration is only clinically significant in $5 \%-15 \%$ of cases.

- A multisystemic approach is required to establish the diagnosis of hepatic sarcoidosis that may resemble primary sclerosing cholangitis on imaging studies.

- While glucocorticoids are the most used first-line therapy, there are no randomised controlled trials for their use in hepatic sarcoidosis. Levels of alkaline phosphatase may remain elevated even after treatment with glucocorticoids. The significance of this finding is unclear.

Acknowledgements We would like to acknowledge Jessica Mayer, a third-year medical student on the team who did an outstanding job connecting with the patient. Thank you to the pathology department in assisting us in obtaining the biopsy images.

Contributors YC contributed research, writing and editing. CC contributed research, writing and editing. LAM contributed overall guidance, direction and editing. All authors read, edited and approved the final document prior to submission.

Funding The authors have not declared a specific grant for this research from any funding agency in the public, commercial or not-for-profit sectors.

\section{Competing interests None declared.}

Patient consent for publication Obtained.

Provenance and peer review Not commissioned; externally peer reviewed.

Open access This is an open access article distributed in accordance with the Creative Commons Attribution Non Commercial (CC BY-NC 4.0) license, which permits others to distribute, remix, adapt, build upon this work non-commercially, and license their derivative works on different terms, provided the original work is properly cited and the use is non-commercial. See: http://creativecommons.org/ licenses/by-nc/4.0/.

\section{REFERENCES}

1 Baughman RP, Field S, Costabel U, et al. Sarcoidosis in America. analysis based on health care use. Ann Am Thorac Soc 2016;13:1244-52.
2 Baughman RP, Teirstein AS, Judson MA, et al. Clinical characteristics of patients in a case control study of sarcoidosis. Am J Respir Crit Care Med 2001:164:1885-9.

3 Porter GH. Hepatic sarcoidosis. A cause of portal hypertension and liver failure; review. Arch Intern Med 1961:108:483-95.

4 Nakanuma Y, Kouda W, Harada K, et al. Hepatic sarcoidosis with vanishing bile duct syndrome, cirrhosis, and portal phlebosclerosis. Report of an autopsy case. J Clin Gastroenterol 2001;32:181-4.

5 Sedki M, Fonseca N, Santiago P, et al. Hepatic sarcoidosis: natural history and management implications. Front Med 2019;6:232.

6 Tan CB, Rashid S, Rajan D, et al. Hepatic sarcoidosis presenting as portal hypertension and liver cirrhosis: case report and review of the literature. Case Rep Gastroenterol 2012;6:183-9.

7 Sghier IA, Billah NM. [Budd-Chiari syndrome: a rare complication of hepatic sarcoidosis (about one case)]. Pan Afr Med J 2016;23:4.

8 De Mulder P, Maertens B, Hoorens A, et al. Extrapulmonary sarcoidosis primarily presenting as cholestatic liver disease. BMJ Case Rep 2019;12:e232618.

9 Bihari C, Rastogi A, Kumar N, et al. Hepatic sarcoidosis: clinico-pathologica characterization of symptomatic cases. Acta Gastroenterol Belg 2015;78:306-13.

10 Romero-Gómez M, Suárez-García E, Otero MA, et al. Sarcoidosis, sclerosing cholangitis, and chronic atrophic autoimmune gastritis: a case of infiltrative sclerosing cholangitis. J Clin Gastroenterol 1998;27:162-5.

11 Alam I, Levenson SD, Ferrell LD, et al. Diffuse intrahepatic biliary strictures in sarcoidosis resembling sclerosing cholangitis. Case report and review of the literature. Dig Dis Sci 1997;42:1295-301.

12 Scherr B, Tromm A, Voigt E. Assoziation von primär sklerosierender Cholangitis und Sarkoidose [Association of primary sclerosing cholangitis and sarcoidosis]. Med Klin 2001;96.

13 Buxbaum J, Papademetriou M, Klipfel N, et al. Biliary sarcoidosis: early diagnosis minimizes the need for surgery. Am J Respir Crit Care Med 2013;187:556-9.

14 Tombazzi C, Waters B, Ismail MK, et al. Sarcoidosis mimicking primary sclerosing cholangitis requiring liver transplantation. Ann Hepatol 2008;7:83-6.

15 Jebran AF, Schmidt WE, Kahraman A, et al. Sarcoidosis of the intra- and extrahepatic bile ducts with concomitant cholangitis in a patient with ulcerative colitis. Case Rep Gastroenterol 2019;13:153-8.

16 Gaduputi V, Ippili R, Sakam S, et al. Extrahepatic biliary obstruction: an unusual presentation of hepatic sarcoidosis. Clin Med Insights Gastroenterol 2015;8:CGast. S22809.

17 Kutaimy R, Mohamad B, Jinjuvadia K. Unusual presentation of sarcoidosis: biliary sarcoidosis mimicking cholangiocarcinoma. Am J Gastroenterol 2018;113:S821.

18 Hamby P, Reizenman A, Walker JP. Laparoscopic management of biliary obstruction secondary to sarcoidosis. Case Stud Surg 2017:3:25.

19 Stinton LM, Bentow C, Mahler M, et al. Pr3-Anca: a promising biomarker in primary sclerosing cholangitis (PSC). PLoS One 2014:9:e112877.

20 Tabibian JH, Bowlus CL. Primary sclerosing cholangitis: a review and update. Liver Res 2017:1:221-30

21 Schep GN, Scully LJ. Primary sclerosing cholangitis and sarcoidosis. Case report and review of the literature. Can J Gastroenterol 1990;4:489-94.

22 Lidar M, Langevitz P, Livneh A, et al. Sclerosing cholangitis associated with systemic sarcoidosis. J Clin Gastroenterol 2003;36:84-5.

23 Lewis J. Histopathology of granulomatous liver disease. Clin Liver Dis 2018:11:77-80.

24 Ungprasert P, Carmona EM, Crowson CS, et al. Diagnostic utility of angiotensinconverting enzyme in sarcoidosis: a population-based study. Lung 2016;194:91-5.

25 Selvan 0 , Vij M, Narasiman G. Sarcoidosis mimicking primary biliary cirrhosis- a clinicopathological description. Tropical Gastroenterology 2016

26 Bass NM, Burroughs AK, Scheuer PJ, et al. Chronic intrahepatic cholestasis due to sarcoidosis. Gut 1982:23:417-21.

27 Ungprasert P, Crowson CS, Simonetto DA, et al. Clinical characteristics and outcome of hepatic sarcoidosis: a population-based study 1976-2013. Am J Gastroenterol 2017:112:1556-63.

Copyright 2021 BMJ Publishing Group. All rights reserved. For permission to reuse any of this content visit

https://www.bmj.com/company/products-services/rights-and-licensing/permissions/

BMJ Case Report Fellows may re-use this article for personal use and teaching without any further permission.

Become a Fellow of BMJ Case Reports today and you can:

- Submit as many cases as you like

- Enjoy fast sympathetic peer review and rapid publication of accepted articles

- Access all the published articles

- Re-use any of the published material for personal use and teaching without further permission

Customer Service

If you have any further queries about your subscription, please contact our customer services team on +44 (0) 2071111105 or via email at support@bmj.com.

Visit casereports.bmj.com for more articles like this and to become a Fellow 